\title{
Still Separate in STEM? \\ Trends in Sex Segregation by Field of Study in Japan, 1975-2019
}

\author{
March 8, 2020 \\ Fumiya Uchikoshi ${ }^{1}$ \\ Ryota Mugiyama ${ }^{2}$ \\ Megumi Oguro ${ }^{3}$ \\ 1: Princeton University, Department of Sociology and Office of Population Research \\ 2: Institute of Economic Research, Hitotsubashi University, Tokyo \\ 3: Graduate School of Education, University of Tokyo
}

Correspondence: Fumiya Uchikoshi, Department of Sociology and Office of Population Research, Princeton University, Princeton, NJ 08540, uchikoshi@princeton.edu. 


\section{Abstract}

There is much evidence to suggest that the gender wage gap in Japan is one of the highest in rich countries, while gender inequality in education at the vertical level is becoming increasingly equalized. A small number of studies suggest that the remaining gender gap can be attributed to horizontal segregation with respect to field of study, particularly female underrepresentation in STEM fields, and little is known about trends in sex segregation by field in Japan specifically. By using publicly available education statistics, the current study investigates these trends from 1975 through 2019. We paid particular attention to (1) different trends in non-STEM, STEM, and health fields, and (2) heterogeneity across national, public, and private institutions. The results of applying Duncan's dissimilarity index to 68 fields of study among four-year university students reveal that the overall trend in sex segregation in field of study has decreased over the 45 years by $43 \%$. We also found that trends differ based on both institutional characteristics of universities and academic field, as the declining segregation trend is mainly driven by the massive integration of men and women in non-STEM fields in private institutions. The declining trend in segregation has been slow in recent years, especially at national and public institutions. We explored potential mechanisms for these stalling trends, and suggest that the driving forces are (1) a slower integration of women in STEM fields and (2) a rise in segregation in health fields. These results provide support for the theory of a stalled gender revolution in Japan. This study concludes that the desegregation may not be linked to the gender equality in the labor market, and that horizontal segregation may even increase because of the growing demand for the workforce to deal with population aging in the future. 


\section{Introduction}

As documented by a wide range of studies, gender inequality in Japan has been persistent and widespread in several domains, including wage or earnings (Chang and England 2011; Hara 2018; Kim and Shirahase 2014; Kumlin 2007; Miyoshi 2008; Takenoshita 2020; Yamaguchi 2019), political representation (Miura 2018), and household labor (Brinton and Oh 2019; Fuwa 2004; Tsuya et al. 2000), making Japan's ranking in gender equality one of the lowest among rich countries (World Economic Forum 2020). ${ }^{1}$ The persistent gender gap is partly attributable to gender inequality in higher education. As the prevalence of women who seek higher education increased in many rich countries (DiPrete and Buchman 2013), female access to four-year universities is increasingly improved, but still lagging behind that of men. While earlier studies have examined trends, determinants, and consequences of the gender gap in access to higher education by focusing on vertical levels of educational attainment measured by years of educational attainment (Brinton 1993; Estévez-Abe 2006, 2011; Hirao 2001), fewer studies have examined sources of the sizable portion of the gender wage gap that remains after controlling for vertical levels of educational attainment.

Drawing on the literature suggesting that horizontal aspects of gender inequality, i.e., segregation by sex for different academic subjects, play an important role in explaining the gender wage gap in Japan (Yamaguchi 2019), the current study examines Japanese trends in sex segregation in field of study. Women outnumber men in humanities and other fields that are often thought of as feminine, while men are more likely to study science and engineering. Particular attention has been paid to the lack of female professionals in STEM fields, as many Japanese scientists have warned that the skewed sex ratio of scientists should be improved (Homma et al. 2013; Kuwahara 2001; Osumi 2006). The limited presence of women in these fields is related not only to inflexible working conditions for scientists that affect work-life balance, but also to unconscious gender bias and to female students studying STEM fields at

\footnotetext{
1 The latest Global Gender Gap study reported that Japan is ranked 121st out of 153 countries.
} 
colleges (Ishikawa et al. 2015; Osumi 2018; Watanabe 2019). These studies all suggest that horizontal segregation in higher education plays an important role in explaining the gender wage gap in Japan, while efforts to examine the trend in sex segregation in field of study in Japan have been limited.

Sex segregation is conceptualized as a skewed distribution of men and women in socially relevant categories, which represents a societal process of sex differentiation. In the United States and in European countries, sex segregation by occupation or field of study has declined over the decades, though the magnitude of change has been stalled in recent years (Barone 2011; England 2010; England and Li 2006; Jacobs 1995; Mann and DiPrete 2003; Turner and Bowen 1999; van de Werfhorst 2017). As such, describing trends in sex segregation in higher education adds to our understanding, providing us with a more detailed view of trends in gender equality in postindustrial economies, where higher education is accessible to a wide range of the population.

Bearing this in mind, this study examines trends in sex segregation in field of study among four-year university students in Japan from 1975 through 2019. Higher education institutions in Japan include junior colleges, which offer associate degrees, and four-year universities, which offer bachelor degrees. By comparison, previous studies often examined sex segregation in higher education by aggregating junior colleges and universities (Charles and Bradley 2002, 2009), but because of the gendered aspects of Japanese junior colleges (FujimuraFanselow 1985, 1995; Starobin 2002), these studies may actually combine qualitatively different institutions. To focus on segregation in a relatively homogeneous setting, this study restricts the cases to segregation within four-year universities.

Within four-year universities, however, trends and patterns of sex segregation in field of study are potentially heterogeneous by establishment type (national, public, and private), the selectivity of which is systematically higher for national or public universities than for private ones. The fields of study that are offered are also different across institutions, with more STEM majors offered by national or public universities than by private ones. Considering the qualitative 
differences across the three institutional settings, the current study expects that we will improve our understanding of the trends and causes of sex segregation in fields of study in Japan by paying special attention to how institutional characteristics interact with the desegregation of men and women in higher education.

\section{Background}

The set of dramatic changes in gender systems that have taken place in the United States since the 1960s is called the gender revolution (England 2010). These changes include (1) an increase in women's labor force participation rates (Cotter et al. 2004), (2) better access to higher education for women, along with the gender gap reversal trend in education (Cotter et al. 2004; DiPrete and Buchman 2013; Morris and Western 1999), (3) desegregation of college majors (England and Li 2006), (4) the enactment of anti-discrimination legislation (Hirsh 2009), and (5) women's increasing political representation (Cotter et al. 2004). Importantly, these shifts in gender systems are not limited to the United States, but applicable to many Western countries (Esping-Andersen 2009; Esteve et al. 2012).

The gender revolution, however, has stalled in recent years (Barone 2011; England 2010; England and Li 2006; Mann and DiPrete 2003; Turner and Bowen 1999; van de Werfhorst 2017). One posited mechanism to explain this stalled trend is a persistent belief in gender essentialism, that is, tacit ideas related to fundamental differences between men and women that are deeply rooted in the social structure (England 2010; Ridgeway 2001; Ridgeway and Correll 2004). Scholars suggest that persistent gender essentialism is expressed as gender-asymmetric change (Ridgeway 2011). In the context of sex segregation, for example, prior studies reported that sex segregation in field of study decreased dramatically during the 1970s through an increase in women's access to traditionally male fields, most notably business fields, but the trend has stalled in recent decades (England and Li 2006; Jacobs 1995). This outcome occurred mainly because male students are less likely to enter fields such as education that are numerically dominated by women (England and Li 2006) and because women's inclination to enter 
traditionally male fields declined, which will lead to occupational sex segregation later in the life course. In this sense, stalling trends in sex segregation in field of study play an important role in what is called the "frozen pipeline" (Milgrom and Petersen 2006) — a bottleneck of gender integration in the labor market.

Although not explicitly mentioned in the stalled revolution theory, also important is that the women's inclination to enter traditionally male fields did not increase uniformly across all fields. In particular, scholars noted that the trend in women's integration in STEM fields has also been stalled since 1990 (England and Li 2006; Jacobs 1995; Xie and Shauman 2003). Paying explicit attention to STEM fields is worthwhile because these fields are linked to the upper end of the average wage distribution among college graduates (Kim et al. 2015), and the gender wage gap is generally lower in STEM occupations than in the overall labor force (Michelmore and Sassler 2016).

These prior studies, however, were mostly focused on Western contexts, limiting our knowledge about whether the same evidence, if any, is observed for non-Western cases. As scholars suggest that gender stratification differs by institutional context (Brinton 1988; Buchman and Charles 1995) and is particularly persistent in East Asian settings (Raymo et al. 2015), it is an important omission that few studies have examined sex segregation in higher education in these gender-inegalitarian locations, such as in Japan. A small number of studies have examined trends in sex segregation in field of study using a comparative perspective, including the Japanese case, revealing that Japan's sex segregation by academic field is higher than in other countries (Charles and Bradley 2002, 2009). These studies, however, included junior colleges (and graduate schools) in their analyses, which in Japan differ in many respects from four-year universities, especially in their heavy emphasis on home economics and in the great prevalence of female students (Fujimura-Fanselow 1985; 1995; Starobin 2002). Since our interests are to describe trends in sex segregation in field of study, with an assumption that the segregation in higher education within the same educational level is one of the important driving forces behind the gender wage gap, this study limited the population of interest to those with the 
same educational level (i.e., university students) to develop insight into how horizontal segregation in higher education, rather than vertical, matters for gender inequality.

\section{The Japanese context}

Implications of lack of women in STEM for gender inequality in the labor market

Horizontal gender segregation in higher education is one of the main explanations for gender inequality in the labor market (Bobbitt-Zeher 2007; Brown and Corcoran 1997; Kalmijn and Van der Lippe 1997; Machin and Puhani 2003), for which a plausible mechanism is through giving access to more skilled occupations including STEM (García-Aracil 2008; He and Zhou 2018; Kim et al. 2015; Morgan et al. 2013; Shauman 2016; van de Werfhorst and Kraaykamp 2001). Because occupational sex segregation has been a major cause of gender wage inequality in postindustrial societies (England 1992; Petersen and Morgan 1995; Tam 1997; TomaskovicDevay and Skaggs 2002; Levanon et al. 2009), segregation in field of study is critical for thinking about gender inequality in the labor market.

Japan has been characterized by its distinctively low representation of women in science (Ishikawa et al. 2014). According to the 2019 government white paper on gender equality (Cabinet Office 2019), for example, women account for only $16.2 \%$ of all scientists, which is the lowest level among OECD countries. The lower representation of women in science fields is particularly distinct in engineering and physical science, as the proportion of female researchers in universities and institutes is only $11.1 \%$ for engineering and $14.6 \%$ for physical science. Importantly, this is caused not only by a smaller number of female students achieving research-related degrees, but also because women are less likely to be interested than men in STEM subjects and thus fail to choose these majors (Isa and Chinen 2016). Female students' lack of confidence in their ability in STEM subjects is larger in Japan than in the United States (Hojo 2015).

Some scholars have suggested that the lack of women in STEM fields is one of the significant causes explaining the gender wage gap in Japan. Several studies argued that 
segregation in choice of major is linked to occupational sex segregation in Japan as well (Yamaguchi 2019). Echoing previous findings on the relationship between occupational sex segregation and the gender wage gap in Japan (Aiba and Wharton 2001; Nakata 1997), Yamaguchi (2019) revealed that a lack of women in STEM majors (science and technology) explains a shortage of women in professional occupations, which contributes to the gender wage gap (but see Brinton and Ngo (1993) or Shirahase and Ishida (1994) on a potentially null association between occupational segregation and wage inequality in Japan).

Although somewhat related to STEM, it is often the case that health fields are treated separately from STEM fields. ${ }^{2}$ As compared with STEM fields, majors in this field, particularly nursing and pharmacy, are overrepresented by female students. Because those who graduated from health fields are more likely to work in female-dominated occupations, which tend to be less rewarding than other STEM fields, separating this group from STEM fields provides important insights into the implications of changing patterns of distribution of men and women in this area for economic gender inequality in the labor market.

\section{Importance of institutional characteristics}

In the context of higher education in Japan, especially when we consider sex segregation in fields of study, it is critical to think about heterogeneity by institutional characteristics, especially establishment type (national, public, and private). The supply of national or public universities has not been sufficient to accept all potential applicants, and these universities are on average more selective, more competitive, and provide a better quality of education. On the other hand, private universities, except for a few schools, are generally thought

2 The U.S. Economics and Statistics Administration (2017), for example, followed this definition in their report on women in STEM. They also admitted, however, that there is less consensus about whether to include other STEM-related fields such as education or healthcare. 
to be in a lower tier (Ishida 1998; Ono 2008). ${ }^{3}$ In comparison with other countries, the beliefs about the university hierarchy have been stable and publicly shared (Yonezawa et al. 2002). Also importantly, as a result of unsupportive public funding for higher education, especially for private universities (Nakazawa 2016), these institutions predominantly offer non-STEM fields that can be established with a limited budget, while STEM fields dominate in national universities. ${ }^{4}$ Reflecting these patterns of fields of study across institutions, female students are more likely to be enrolled in private universities than in national or public universities. ${ }^{5}$ As the capacities of national and public institutions to meet the growing demand for higher education have been limited, it was market-oriented private institutions that contributed to the expansion of higher education, especially for women, in the Japanese context.

The interrelationship between establishment type, school selectivity, and the distribution of fields of study provides understudied, but potentially important, insights into the gender inequality in Japan. The low representation of women in STEM fields suggests smaller or even no changes in sex segregation there, leading to an expectation that desegregation in fields of study, if any, is driven by an integration of male and female students in non-STEM fields including health. Importantly, as we discussed above, fields of study in Japan are correlated with

3 According to Times Higher Education's Japan University Rankings 2019 (https://japanuniversityrankings.jp/), 9 out of top 10 universities are national, and all but 15 of the top 50 and 37 of the top 100 universities are private institutions. Since national or public universities accounted for only $32.9 \%$ of the total number of universities in 2018 , the overrepresentation of these universities in the rankings supports my claim that national or public universities are perceived to be more prestigious.

${ }^{4}$ In 2018, more than half of students in private universities majored in humanities or social sciences, while the proportion was $22 \%$ for national university students (Ministry of Education, Culture, Sports, Science, and Technology 2019).

${ }^{5}$ In $2016,80 \%$ of female students were enrolled in private universities, while $14 \%$ of them were enrolled in national universities. The proportion of men is $76 \%$ for private and $20 \%$ for national universities. 
school selectivity, where national universities are more selective, followed by public and then private universities. An implication of this evidence is that desegregation trends might be particularly prevalent for non-STEM majors in private universities, and this is mainly explained by women's changing choices of major, benefitting from the massive educational expansion led by the private sector. Also, the degree of desegregation in fields of study might be smaller for national or public universities, which have limited capacities to accept the emerging female population into higher education because of the emphasis on STEM fields and women's disinclination to choose STEM fields. If this expectation is correct, it may provide a novel interpretation about an apparent contradiction between the persistent gender wage gap and a constant decline in occupational sex segregation in Japan over the four decades (Charles et al. 2004; Uchikoshi and Mugiyama 2020a, 2020b). Specifically, sex segregation could decline while economic gender inequality in the labor market remains if (1) desegregation is driven by an integration of fields of study that are linked to less-rewarding occupations rather than to STEM and (2) the degree of integration is smaller for selective universities (national universities in particular).

\section{The changing face of private universities}

The major role played by the private universities in women's improved access to fouryear universities is evidenced by Figure 1, which shows the proportion of student enrollment at the university level in private universities. The proportion continuously increased for both men and women during the expansion of higher education, including establishment of new private universities, from the late 1950s to the late 1970s. Room for expansion during the 1990s and afterward was also provided through newly-established private universities. ${ }^{6}$ Importantly, during

6 The expansion was initiated by the Ministry of Education's announcement in 1984 that relaxed its restrictions on establishing new institutions to meet the demand of a growing younger population (Ishida 2007). 
this period, the growth of the proportion of private university students was larger for women than for men. The increase in the share of female students in private institutions was caused by the upgrading of junior colleges to private universities. Junior colleges are mostly established by private institutions (the percentage of private institutions was $83.9 \%$ in 1995) and are frequently characterized by their concentration of female students, constituting, for example, almost $90 \%$ of students enrolled in junior colleges during the 1980s (Ministry of Education, Culture Sports, Science and Technology 2019). Another gendered aspect of these junior colleges is the subjects that women have majored in, which are mostly humanities, home economics, education, or nursing (Fujimura-Fanselow 1985, 1995; Starobin 2002). While more than 500,000 students (mostly female) were enrolled in these junior colleges in the early 1990s, opportunities for occupational careers that opened to women led to more female students aspiring to study at fouryear universities. As a result, many junior colleges that started to suffer from a shortage of female students changed from providing associate degrees to providing bachelor's degrees ( $\mathrm{Li}$ 2019). The number of junior colleges in Japan decreased almost by half, from 596 in 1995 to 337 in 2017, while the number of private four-year universities increased from 415 to 604 during the same period (Ministry of Education, Culture Sports, Science and Technology 2019). Importantly, these upgraded institutions are located around the lower ranks of the hierarchy, accepting more students by lowering selectivity. This suggests the growing heterogeneity of private universities in terms of school prestige (Uchikoshi 2019).

[Figure 1 is about here]

\section{Research questions}

The aim of this study is to provide a descriptive account of trends in sex segregation in field of study among college students in Japan, which are characterized by persistent gender inequality and lack of women in STEM fields. To achieve this goal, the current study draws on the data 
from an administrative survey on educational statistics to explore whether the theory of a stalled gender revolution is applicable to the gender-unequal setting. Has sex segregation in field of study declined, yet stalled in recent years, as prior studies revealed? If so, is this stalling trend driven by the slower integration of male students into traditionally female fields, fewer female students choosing male fields, particularly STEM fields, or both? Do these trends differ by institutional characteristics?

To answer these questions, we describe trends in sex segregation in field of study with a particular focus on (1) non-STEM, STEM, and health fields, and (2) 16 subfields across these categories that contribute substantially to the observed segregation $(75 \%)$. We also aim to examine the institutional heterogeneity across national, public, and private institutions. Last, changes in sex segregation could be impacted through two different mechanisms, one compositional change across majors and the other from changing sex distribution within a given major, that point to the value of decomposing changes in segregation trends into their separate contributions. Therefore, in addition to describing overall trends, we distinguish (1) compositional changes in the field of study (college major mix effect) from (2) changes in segregation within college majors (sex composition effect) and quantify these contributions using a decomposition method.

\section{Data, method, and variables}

The current study draws data from School Basic Surveys for four-year university students, which offer publicly available administrative data collected by the Ministry of Education, Culture, Sports, Science and Technology (MEXT) annually from 1948 to the present. Aggregated School Basic Survey data was obtained from the government's website (https://www.e-stat.go.jp/). We present trends in sex segregation in field of study over time by constructing a harmonized classification scheme from 1975 through 2019. While it would be possible to add older data to the analysis, School Basic Surveys made minor changes to the classification each year, and the classification schemes of field of study before 1975 are less compatible with those in 1975 and 
beyond. The fields of study in School Basic Surveys are reclassified to 68 categories, as shown in Table 1. Male or female students in a given year in a given field are grouped by institution type (national, public, and private).

[Table 1 about here]

To show the trends in sex segregation in field of study, we used Duncan's dissimilarity index (Duncan and Duncan 1955), as other studies did (England and Li 2006; Jacobs 1995). If the number of female (male) students in field of study $j$ in time $t$ is defined as $F_{j t}\left(M_{j t}\right)$, then the dissimilarity index can be expressed as a sum of absolute differences between the proportion of female students in a given field $\left(F_{j t} / F_{t}\right)$ and that of male students $\left(M_{j t} / M_{t}\right)$. This index refers to the percentage of women (or men) that need to be transferred to another field of major in order to make the distribution of field of study between men and women equal. For example, a value of 100 means that the distributions of men and women are as different as possible, while a value of zero means that the distribution of field of major between men and women is exactly the same.

$$
D_{t}=\sum_{j}\left[100 \times \frac{1}{2} \times\left|\frac{F_{j t}}{F_{t}}-\frac{M_{j t}}{M_{t}}\right|\right]=\sum_{j} D_{j t}
$$

To investigate the detailed trends in sex segregation in higher education by different types of fields, we separate the overall segregation index $D_{t}$ into contributions by each type of fields, i.e., non-STEM, STEM, and health, as follows:

$$
D_{t}=\sum_{j \in \text { Non-STEM }} D_{j t}+\sum_{j \in S T E M} D_{j t}+\sum_{j \in \text { Health }} D_{j t}
$$


Non-STEM fields include humanities, social sciences, and other professional majors that are not recognized as having STEM field-like pedagogy. STEM includes physical sciences, engineering, and agricultural sciences. ${ }^{7}$ Health fields consist of five subfields and is equivalent to the Health category in Table 1. These include some STEM-related fields in terms of subjects that students are supposed to study. However, as STEM is the abbreviation of Science, Technology, Engineering, and Math, it does not include healthcare-related fields.

A series of descriptive findings regarding trends in sex segregation in field of study, however, suffers from evaluating changes in segregation within a given field. In other words, overall changes in segregation may be driven solely by compositional shifts in certain fields. For example, the decline in segregation could be explained by a decrease in fields in which men are overrepresented without any change in the segregation of men and women within the field. To solve this problem in using Duncan's segregation index, we applied a decomposition method (Blau and Hendricks 1979; Fuchs 1975) to allows us to evaluate contributions to overall segregation separately by (1) compositional shifts in fields of study (college major mix effect) and (2) changes in segregation within fields (sex composition effect). This decomposition method separates two types of effects for changes in sex segregation between $t=2$ and $t=1$ as follows;

$$
\begin{aligned}
D_{2}-D_{1}= & \sum_{j}\left[D_{j 2}-100 \times \frac{1}{2} \times\left|\frac{\frac{F_{j 2}}{T_{j 2}} \times T_{j 1}}{\frac{F_{2}}{T_{2}} \times T_{1}}-\frac{\frac{M_{j 2}}{T_{j 2}} \times T_{j 1}}{\frac{M_{2}}{T_{2}} \times T_{1}}\right|\right] \\
& +\sum_{j}\left[100 \times \frac{1}{2} \times\left|\frac{\frac{F_{j 2}}{T_{j 2}} \times T_{j 1}}{\frac{F_{2}}{T_{2}} \times T_{1}}-\frac{\frac{M_{j 2}}{T_{j 2}} \times T_{j 1}}{\frac{M_{2}}{T_{2}} \times T_{1}}\right|-D_{j 1}\right]
\end{aligned}
$$

7 While the original classification categorized crafts as engineering, we incorporated 27: crafts into non-STEM. 
$T_{j t}$ indicates the total number of male and female students in the field $j$ in time $t\left(T_{j t}=M_{j t}+\right.$ $F_{j t}$ ). The first term (major mix effect) indicates to what extent the $\mathrm{D}$ index would have been altered by the change in the share of each field if the sex composition in each field was fixed. The second term (sex composition effect) indicates to what extent $\mathrm{D}$ index would have been altered by the change in the sex composition in each field of study if the share of each field was fixed.

\section{Results}

\section{Descriptive findings}

Figure 2 presents trends in sex segregation measured by Duncan's index over the 45 years, with results broken out by institutional setting (national, public, and private) ${ }^{8}$ As of 1975 , the segregation index measured by detailed classification was 68.1 , indicating that we need to move $68 \%$ of men or women to make the distribution of majors for them equal. There has been a consistent decline in sex segregation in field of study over the last 45 years. In 2019, the segregation index was 38.9 , indicating that segregation has been reduced by about $43 \%$ over the past 45 years. The declining trend in segregation, however, has been stalled in the last 15 years. This result is similar to the trends observed in the United States, supporting England's (2010) thesis on the stalled gender revolution.

Despite the overall declining trend in segregation, the trend differs depending on institutional settings. Segregation in private institutions has changed most dramatically, declining by 30 from 69.1 to 39.1 ( $43 \%$ decline). In contrast, the national institution had slightly less desegregation with a decline of 28.1, from 65.1 in 1975 to 37.0 in 2019, while the upward or

\footnotetext{
${ }^{8}$ We also examined trends based on 11 aggregated fields (results not shown), which indicated that the overall trend was similar to trends using detailed categories regardless of institutional characteristics.
} 
stalled trend in segregation is observed in the 2000s. The trend for public institutions falls in between in terms of the percent change, as the segregation index declined from 65.2 in 1975, which is the same as that in national universities, to 43.3 in 2019.

[Figure 2 about here]

To what extent do each of the three major fields of study, non-STEM, STEM, and health, contribute to this trend? Table 2 presents the contribution of each area to the overall segregation index at four points in time $(1975,1990,2005$, and 2019). As this table shows, the main driver of the declining trend in segregation is the non-STEM fields, regardless of institutional setting. For example, the contribution to the segregation index by non-STEM fields across all universities in 1975 was 50.1, accounting for about $73 \%$ of overall segregation. Segregation in this field declined dramatically over the 45 years, falling by $56 \%$ to 22.1 . Due to the massive decline in segregation in non-STEM fields, its contribution to overall segregation decreased to $56.8 \%(=22.1 / 38.9)$. The declining trend in non-STEM fields is especially the case at national universities, where segregation decreased from 39.3 to 13.7 (a $65 \%$ decline).

In contrast to this trend, the decline in segregation in STEM fields is slow, from 14.4 to 10.8 (a $25 \%$ decline). In public institutions, segregation in these fields even increased from 9.1 to 13.6. Trends in health fields described a U-shape. Over the first 15 years, from 1975 to 1990, the segregation in this field declined, but it increased in recent years. Across all institutions, the segregation in 2019 is larger than that in 1975.

[Table 2 about here]

To better understand what is driving the overall trend in segregation, we next focus on selected fields, as we show the trends in the proportion of female $\left(F_{j} / F\right)$ and male $\left(M_{j} / M\right)$ in a given field $j$ in selected fields in Figures 3 to 6 . We chose 12 fields in 1975 that accounted for 
$75 \%$ of all degrees (i.e., literature, law and politics, commerce and economics, sociology, mechanical engineering, telecommunication engineering, civil engineering, applied chemistry, pharmacy, pedagogy: general, elementary school education, and music). We also added four fields that account for $75 \%$ of all degrees in 2019 but does not for 1975 (humanities: others, engineering: others, nursing, and pedagogy: others).

These figures provide three important findings. First, the two fields that contributed mainly to desegregation were 1) literature and 2) commerce and economics. On the one hand, in $1975,29 \%$ of women majored in literature, while only about $4 \%$ of men majored in this field. As of 2019 , the percentage of men majoring in literature had slightly declined to $2.8 \%$, while that of women plunged to $8.8 \%$. Literature was traditionally a female major, but the result suggests that this character is rapidly disappearing. On the other hand, the proportion of men who majored in economics has decreased, contributing to the declining trend in segregation in this field. In 1975, $33.8 \%$ of men majored in commerce or economics, while the proportion was only $6 \%$ for women. The proportion of men majoring in this field, however, dropped to $24.2 \%$ in 2019 , while it increased to $12.6 \%$ for women.

Second, as we confirmed in Table 2, there has been barely any change in the STEM fields overall. In some fields, such as civil engineering and applied chemistry, the separation has declined, as the number of males majoring in these fields decreased while at the same time more women chose these fields. In contrast, in other fields, such as engineering: others, the segregation increased as the number of males majoring in this field increased. Although there are some changes in segregation in individual STEM fields, the degree of change as a whole is relatively smaller than in non-STEM or health fields and is largely stable.

[Figure 3 about here]

Third, there is a significant variation in some of the 16 fields across institutions. Trends in the proportion of women and men differ considerably in nursing and education. In general, the 
nursing field has contributed to more segregation, but this trend is particularly the case in public universities. Until around the 1990s, there were almost no students this field, meaning that there was no segregation, but the proportion of female students studying this field increased to $21 \%$ in recent years, while there was only a slight increase in this field for male students. As for elementary school education, there was greater female representation. However, it was only national universities that accounted for the prevalence of students majoring in this field. In 1975, almost $40 \%$ of women in national universities majored in this field, while this was less than $10 \%$ for male students. Female representation in this field decreased dramatically over the decades, and about $5 \%$ of all women in national institutions majored this field in recent years. In contrast to this declining trend, female students increasingly major in pedagogy: others (such as lifelong education).

[Figure 4 about here]

[Figure 5 about here]

[Figure 6 about here]

\section{Decomposition results}

Figures 7 to 10 present the decomposition results. Since this decomposition method is calculated by taking a difference in the segregation index at two points, results look different depending on which two periods we select. Therefore, we show four decomposition results: 1975-1990, 1990-2005, 2005-2019, and 1975-2019. Figure 7 presents results for all university students, showing that the sex composition effect is a major driver of the declining segregation over the 45 years. Therefore, it was not the decrease in the size of fields that are represented by more women or men, or the increase in the size of integrated fields, but the desegregation within fields of study that contributed most to declining segregation. Specifically, the sex composition effect contributed to desegregation by 29.9 , while the major mix effect contributed to an increase in segregation by 1.0. Also, as we confirmed in the previous section, it was changes in 
segregation within non-STEM fields, which accounts for $92 \%$ of the decline by the sex composition effect, rather than ones within STEM $(0 \%)$ or health fields $(8 \%)$, that contributed to the major part of the declining trends. Stalled trends in integration in the last 15 years are also explained by the relatively limited contribution by sex composition effect in non-STEM fields; the sex composition effect in these fields decreased segregation by 11.4 and 12.6 for each of 1975-1990 and 1990-2005, but the contribution to desegregation was 4.9 for 1975-2019.

[Figure 7 about here]

The finding that a large part of the decline in sex segregation in field of study (and its slower pace in recent years) is explained by the sex composition effect in non-STEM majors was also the case across different institutional settings, especially for private institutions, which account for most of the university students in Japan (Figure 10). The results also indicate, however, that the major mix effect does play a role in explaining segregation trends. In particular, the major mix effect in health fields contributes to increasing segregation, especially for national and public universities from 1990 to 2005 as shown in Figures 8 and 9. Detailed analysis (not shown here) suggests that this is mainly driven by an increase in the size of maledominated fields (engineering) and female-dominated fields (nursing).

[Figure 8 about here]

[Figure 9 about here]

[Figure 10 about here]

\section{Discussion}

The current study provided a descriptive account of trends in sex segregation in field of study in Japan over the 45 years from 1975 through 2019. Access to four-year universities had previously been highly unequal between men and women, but women's access to higher education has 
become close to that of men in recent years. As the vertical level of educational inequality diminished, it became critical to study to what extent the horizontal level of educational inequality remains. This question is particularly relevant to the lack of women in STEM fields in OECD countries, where the proportions of female scientists and researchers are still low.

Using the administrative data on educational statistics, our results revealed four points. First, sex segregation in field of study decreased dramatically over the past 45 years, dropping by $43 \%$. This declining trend is uniform across all institutional settings. Second, however, the decline in sex segregation was mainly driven by the integration of men and women within nonSTEM fields, particularly for private institutions (see Figure 10), and somewhat by integration within health fields, rather than within STEM fields. Third, a detailed analysis of trends in sex segregation in each field suggests that a major part of the decline in segregation is explained by the decline in female students majoring in literature and the convergence of men and women choosing commerce and economics. ${ }^{9}$ The disinclination of females to study elementary school education is also a driving force for declining segregation, although this major is concentrated in national universities, resulting in a limited contribution to the general trend. Results also suggest that female students, especially at public universities, increasingly major in nursing fields that contribute to the rise in segregation of health fields. Last, the decline in sex segregation is further explored through decomposition analysis, suggesting that the driving force behind the declining trend is desegregation within fields of study, again especially for non-STEM fields, rather than

\footnotetext{
9 The declining segregation in economics is possibly remarkable in Japan, in the sense that
} economics is the field that shares the same slower convergence with STEM fields in the United States (England and Li 2006; Mann and DiPrete 2013). However, this field includes not only economics majors but also business majors (commerce), which have seen a dramatic convergence of men and women in the US (England and Li 2006). It is unfortunate that we cannot distinguish these two majors separately, but the changes in segregation in economics and commerce fields might be attributable to the larger convergence in business-related majors than in economics majors. 
the compositional shifts in fields. Compositional shifts in health fields even contributed to the growing segregation in recent years.

One of the main findings - a consistent decline in sex segregation in higher education, although stalled in recent years - seems counterintuitive, given that numerous studies argued that gender inequality both in the labor market and in households has been persistent in Japan (Brinton 1993, 2011; Raymo et al. 2015; Rosenbluth 2007). This result is understandable, however, in the sense that, as we expected, desegregation has been driven by changing sex composition within non-STEM fields in private universities, which is likely to be linked to the less rewarding occupations. As Yamaguchi (2019) compellingly argued, professional occupations numerically dominated by men explain a sizable proportion of the gender wage gap in Japan, and the lack of women in professional occupations is caused by women's disinclination to study STEM majors. Results in this study echo his argument. Specifically, the major part of the decline in sex segregation in field of study is caused by the integration of non-STEM fields. In contrast, desegregation in STEM fields has been slow. By separating the overall segregation index into three major fields, the current study provides descriptive but compelling evidence that resonates with the persistent gender wage gap in Japan.

Furthermore, although speculative, these findings, i.e., desegregation driven by nonSTEM fields and the persistence of segregation in STEM fields, could be explained by contextual factors in Japan's higher education system characterized by widely shared university prestige that favors national institutions over private ones. As argued above, national and public universities are often perceived to be more competitive and prestigious in Japan (Ishida 1998; Ono 2008). Also, STEM fields are dominant in the national universities, while non-STEM fields are predominantly offered by private institutions. Importantly, this is especially the case for institutions at the lower end of the hierarchy. Female students' inclination to enroll at private 
institutions thus is greater for universities at the lower end of the hierarchy. ${ }^{10}$ From these patterns, we speculate that the declining segregation via changing sex composition in non-STEM fields is driven by an increase in newly created, less competitive private universities, including ones upgraded from junior colleges, while the segregation in STEM fields has been stable because these fields are predominantly offered in national universities and thus are not influenced by the expansion of private institutions. If this is the case, then declining segregation in non-STEM fields does not imply an integration of male and female students across these fields within the same institution. The same story might apply to the rise in the segregation of health fields, because this trend is also driven by newly created universities, but caution is needed for this interpretation, as public universities are perceived to be more prestigious than private ones, especially in rural areas, and nursing departments are as competitive as other departments in public universities.

Also, we acknowledge the limitations of this study. In particular, the current study was not able to distinguish private institutions that were upgraded from junior colleges from other

10 To see the relationship between university prestige and the distribution of majors, we used the 2015 Social Stratification and Mobility survey, a cross-sectional study conducted from January to June 2015 targeting respondents aged from 20 to 79 at the end of 2014 , to apply the university classification scheme developed by Yonezawa (2008) and Kaneko (1996). Based on the classification (see Appendix for details), we examined how the distribution of majors differs by university prestige and sex. According to Appendix Table 1, women were more likely to graduate from private universities established after 1960 than were men. Table 2 shows that STEM majors are smaller for graduates from private universities established after 1960 than from ones established before that, especially for men, while STEM majors are the least prevalent for core private university graduates. Instead of the smaller share of STEM majors for nonselective private universities established after 1960, these universities offer health majors, rather than non-STEM ones. These results are generally similar to results in Hamanaka (2016)'s study using a representative cross-sectional survey for private university students who were enrolled at the time of survey (November 2014). 
four-year universities. The upgrading of junior colleges suggests that institutions offering majors that are traditionally female, such as humanities and education, were likely to increase in recent decades, contributing to a stalled or even increased trend in sex segregation. If this is the case, we expect to see that the slow convergence in field of study between men and women suggested by the stalled gender revolution theory might be explained by an increase in private institutions, some of which were upgraded from junior colleges. Therefore, in future studies, it is worth examining to what extent the upgrading of junior colleges to private universities has contributed to the increase in the female share of university students and to the quantity of sex segregation in field of study. Also importantly, newly established private institutions, including these upgraded ones, are located around the lower ranks of the university hierarchy because they have employed less selectivity to recruit more students. This contributes to the growing heterogeneity of higher education by institutional prestige, which we are not able to examine in this study. As we speculated above, future studies need to examine potentially heterogeneous patterns of segregation in fields of study across institutions with different institutional prestige.

\section{Conclusion}

We provide two substantive contributions to the literature on sex segregation in field of study and on gender inequality in general. First, the current study provides descriptive evidence that overall segregation consistently declined and then stalled, while sex segregation in STEM fields remains persistent. The former finding supports England's (2010) thesis on the stalled gender revolution, as we also saw that the dramatic decline in sex segregation is driven by more women moving out of traditionally female fields, such as humanities and elementary school education, and choosing traditionally male dominated fields, such as business (England and Li 2006). In contrast, the decline in segregation during the second half of the time period was stalled because women's transition from female dominated fields to male dominated ones has been slowing down, while there is no explicit trend in men choosing traditionally female dominated fields. The latter finding is also consistent with the trends observed in the United States, in the sense that 
women's inclination to enter some traditionally recognized male fields is not the case for STEM fields, which explains the remaining gender wage gap (England and Li 2006; Kim et al. 2015; Michelmore and Sassler 2016).

Second, our analysis by institutional characteristics shows that there is a rising trend in segregation in some fields. Specifically, nursing fields, especially at public universities, increased in segregation in recent years through more women than men entering this field (Figures 5 and 9). Public universities, by nature, are expected to meet the demand in municipalities that support the institution. As the demographic composition shifts, with an aging population, municipalities are facing increasing demands for medical and health industries. Indeed, 31 public universities with nursing departments were established between 1993 and 2000, 18 of which are schools that have only nursing or medical departments, while four more include nursing or medical departments (Takahashi 2009).

The various institutional incentives and financial supports that encourage the establishment of nursing or medical departments are themselves gender-neutral. ${ }^{11}$ However, as nursing fields are still predominantly female, these gender-neutral policies unintentionally contributed to growing segregation in higher education. Although we need to admit that the share of total enrollments in nursing fields or public universities is small, nevertheless it is worth emphasizing that population aging at the global level suggests that this finding could be applicable to other societies in the future. Indeed, according to the Current Population Survey,

11 These include MEXT's announcement in 1991 that universities are allowed to establish new nursing departments and the Ministry of Home Affairs' promotion of financial supports to establish nursing departments (Takahashi 2009). MEXT's announcement diverged from the series of national policies from 1989: in contrast to their regulation to control student numbers by setting fixed quotas, it obliged municipalities to take steps to develop human resources in nursing, including the establishment of nursing department or universities. The funding mechanism offered by the Ministry of Home Affairs was operated through the distribution of local allocation taxes or preferential treatment in municipal bonds. 
the nursing workforce in the United States increased from 2.5 million in 2010 to 3.2 million in 2018, and is expected to grow 12 percent from 2018 to 2028 (U.S. Bureau of Labor Statistics 2020). Since the nursing occupation remains one of the most female-dominated fields and is a major source of the gender wage gap (Hegewisch and Hartman 2014), the slower pace of sex integration in field of study and vocation caused by the growth of these largely female occupations might continue (Bailey and DiPrete 2016) and thus need to be paid more attention.

To conclude, this study contributed to previous studies by adding the Japanese case, which has been less examined but suggests a similar trend with that of Western countries. This study also provided suggestive evidence for two conclusions. One is that the slow integration of STEM fields might be a cause of the persistent gender wage gap, and the other is that horizontal aspects of educational inequality may increase because of the growing demand for the workforce to deal with the aging population. These accounts, provided by the current study, are descriptive, but could be causal. One possible extension for future study would be to examine whether the slow convergence of men and women in STEM fields is causally linked to the persistent wage gap in Japan.

\section{Acknowledgements}

Research reported in this publication was supported by The Eunice Kennedy Shriver National Institute of Child Health \& Human Development of the National Institutes of Health under Award Number P2CHD047879 and the JSPS Grant-in-Aid for Specially Promoted Research (Grant number 25000001). We thank Kaoru Sato, Kohei Toyonaga (University of Tokyo), Daiki Hiramori (University of Washington), Hirofumi Taki (Hosei University), and Kyoko Komatsu (Ochanomizu University) for their helpful comments and suggestions, and the 2015 SSM Survey Management Committee for allowing us to use the SSM data. 


\section{Reference}

Aiba, Keiko and Amy S. Wharton. 2001. "Job-Level Sex Composition and the Sex Pay Gap in a Large Japanese Firm.” Sociological Perspectives 44(1):67-87.

Bailey, Martha J. and Thomas A. DiPrete. 2016. "Five Decades of Remarkable but Slowing Change in U.S. Women's Economic and Social Status and Political Participation." RSF: The Russell Sage Foundation Journal of the Social Sciences 2(4):1-32.

Barone, Carlo. 2011. "Some Things Never Change: Gender Segregation in Higher Education across Eight Nations and Three Decades.” Sociology of Education 84(2):157-76.

Bobbitt-Zeher, Donna. 2007. "The Gender Income Gap and the Role of Education." Sociology of Education 80(1):1-22.

Brinton, Mary C. 1988. "The Social-Institutional Bases of Gender Stratification: Japan as an Illustrative Case." American Journal of Sociology 94(2):300-334.

Brinton, Mary C. 1990. “Intrafamilial Markets for Education in Japan.” Pp. 307-330 in Social Institutions: Their Emergence, Maintenance and Effects, edited by M. Hechter, K. Opp, and R. Wippler. New York: Aldine de Gruyter.

Brinton, Mary C. 1993. Women and the Economic Miracle: Gender and Work in Postwar Japan. California: University of California Press.

Brinton, Mary C., ed. 2001. Women's Working Lives in East Asia. Stanford University Press. Brinton, Mary C. and Eunsil Oh. 2019. “Babies, Work, or Both? Highly Educated Women's Employment and Fertility in East Asia.” American Journal of Sociology 125(1):105-40.

Brinton, Mary C. and Hang-Yue Ngo. 1993. "Age and Sex in the Occupational Structure: A United States-Japan Comparison.” Sociological Forum 8(1):93-111.

Brown, Charles and Mary Corcoran. 1997. "Sex-Based Differences in School Content and the Male-Female Wage Gap.” Journal of Labor Economics 15(3):431-65.

Buchmann, Marlis, and Maria Charles. 1995. “Organizational and Institutional Factors in the Process of Gender Stratification: Comparing Social Arrangements in Six European Countries.” International Journal of Sociology 25(2):66-95. 
Cabinet Office. 2019. White Paper on Gender Equality. Retrieved January 2, 2020(http://www.gender.go.jp/about_danjo/whitepaper/r01/zentai/index.html).

Chang, Chin-fen, and Paula England. 2011. "Gender Inequality in Earnings in Industrialized East Asia." Social Science Research 40(1):1-14.

Charles, Maria and Karen Bradley. 2002. "Equal but Separate? A Cross-National Study of Sex Segregation in Higher Education.” American Sociological Review 67(4):573.

Charles, Maria and Karen Bradley. 2009. "Indulging Our Gendered Selves? Sex Segregation by Field of Study in 44 Countries." American Journal of Sociology 114(4):924-76.

Charles, Maria, Mariko Chang, and Joon Han. 2004. "Gender and Age in the Japanese Labor Market, 1950-1995." Pp. 179-212 in Occupational Ghettos: the Worldwide Segregation of Women and Men, edited by M. Charles and D. B. Grusky. Stanford, Calif: Stanford University Press.

Cotter, Hermsen, Reeve Vanneman, and Joan Hermsen. 2004. Gender Inequality at Work. Russell Sage Foundation.

DiPrete, T. A. and C. Buchmann. 2013. The Rise of Women: The Growing Gender Gap in Education and What It Means for American Schools. Russell Sage Foundation.

Duncan, Otis Dudley and Beverly Duncan. 1955. "A Methodological Analysis of Segregation Indexes." American Sociological Review 20(2):210-17.

England, Paula. 1992. Comparable Worth: Theories and Evidence. New York: Routledge. England, Paula. 2010. “The Gender Revolution: Uneven and Stalled.” Gender \& Society 24(2):149-66.

England, Paula and Su Li. 2006. "Desegregation Stalled: The Changing Gender Composition of College Majors, 1971-2002." Gender \& Society 20(5):657-77.

Esping-Andersen, G. 2009. Incomplete Revolution: Adapting Welfare States to Women's New Roles. Polity. 
Esteve, Albert, Joan Garcia-Roman, and Inaki Permanyer. 2012. "The Gender-Gap Reversal in Education and Its Effect on Union Formation: The End of Hypergamy?" Population and Development Review 38(3):535-46.

Estévez-Abe, Margarita. 2006. “Gendering the Varieties of Capitalism. A Study of Occupational Segregation by Sex in Advanced Industrial Societies.” World Politics 59(1):142-75.

Estévez-Abe, Margarita. 2011. “Gendered Consequences of Vocational Training.” Pp. 259-83 in The Political Economy of Collective Skill Formation, edited by M. R. Busemeyer and C. Trampusch. Oxford University Press.

Fuchs, Victor R. 1975. “A Note on Sex Segregation in Professional Occupations.” Explorations in Economic Research 2:105-111.

Fujimura-Fanselow, Kumiko. 1985. “Women's Participation in Higher Education in Japan.” Comparative Education Review 29(4):471-89.

Fujimura-Fanselow, Kumiko. 1995. “'College Women Today: Options and Dilemmas.” Pp. 125-54 in Japanese Women: New Feminist Perspectives on the Past, Present, and Future, edited by K. Fujimura-Fanselow and A. Kameda. New York: The Feminist Press

Fuwa, M. 2004. "Macro-Level Gender Inequality and the Division of Household Labor in 22 Countries." American Sociological Review 69(6):751-67.

García-Aracil, Adela. 2008. “College Major and the Gender Earnings Gap: A Multi-Country Examination of Postgraduate Labour Market Outcomes." Research in Higher Education 49(8):733-57.

Hamanaka. Yoshitaka. 2016, Students and Education at Private Universities. Paper distributed at Council for the Promotion of Private Universities. April 13.

Hara, Hiromi. 2018. "The Gender Wage Gap across the Wage Distribution in Japan: Within- and between-Establishment Effects." Labour Economics 53:213-29.

He, Guangye and Muzhi Zhou. 2018. "Gender Difference in Early Occupational Attainment: The Roles of Study Field, Gender Norms, and Gender Attitudes.” Chinese Sociological Review 50(3):339-66. 
Hegewisch, Ariane, and Heidi Hartmann. 2014. "Occupational Segregation and the Gender Wage Gap: A Job Half Done."

Hirao, Keiko. 2001. "Mothers as the Best Teachers: Japanese Motherhood and Early Childhood Education.” Pp. 180-203 in Women's Working Lives in East Asia. Palo Alto, CA: Stanford University Press.

Hirsh, C. Elizabeth. 2009. "The Strength of Weak Enforcement: The Impact of Discrimination Charges, Legal Environments, and Organizational Conditions on Workplace Segregation.” American Sociological Review 74(2):245-71.

Hojo, Masakazu. 2015. "Sugaku gakushu no danjosa ni kansuru Nichi-Bei hikaku” (The gender gap in mathematics: Evidence from Japan and the United States). The Journal of Economics, Niigata University 99:1-15. [In Japanese]

Homma, Miwako Kato, Reiko Motohashi, and Hisako Ohtsubo. 2013. “Japan's Lagging Gender Equality." Science 340(6131):428-29.

Isa, Natsumi, and Ayumu Chinen. 2016. "Gender Disparities in Academic Performance and Motivation in STEM Subjects in Japan.” Japan Labor Review 13(3):101-21.

Ishida, Hiroshi. 1998. "Educational Credentials and Labour-Market Entry Outcomes in Japan." Pp. 287-309 in From School to Work: A Comparative Study of Educational Qualifications and Occupational Destinations, edited by Y. Shavit and W. Muller. Clarendon Press. Ishida, Hiroshi. 2007. "Japan: Educational Expansion and Inequality in Access to Higher Education," Pp. 63-86 in Stratification in Higher Education: A Comparative Study, edited by Y. Shavit, R. Arum, and A. Gamoron. Stanford: Stanford University Press.

Ishikawa, Mayumi, Ashlyn Moehle, and Shota Fujii. 2014. "Japan: Restoring Faith in Science through Competitive STEM Strategy.” Pp. 81-101 in The Age of STEM: Educational policy and practive across the world in Science, Technology, Engineering and Mathematics. Routledge.

Jacobs, Jerry A. 1995. “Gender and Academic Specialties: Trends among Recipients of College Degrees in the 1980s." Sociology of Education 68(2):81. 
Kalmijn, Matthijs and Tanja Van der Lippe. 1997. "Type of Schooling and Sex Differences in Earnings in the Netherlands." European Sociological Review 13(1):1-15.

Kim, ChangHwan, Christopher R. Tamborini, and Arthur Sakamoto. 2015. "Field of Study in College and Lifetime Earnings in the United States." Sociology of Education 88(4):320-39.

Kim, Young-Mi, and Sawako Shirahase. 2014. "Understanding Intra-Regional Variation in Gender Inequality in East Asia: Decomposition of Cross-National Differences in the Gender Earnings Gap.” International Sociology 29(3):229-48.

Kumlin, J. 2006. “The Sex Wage Gap in Japan and Sweden: The Role of Human Capital, Workplace Sex Composition, and Family Responsibility.” European Sociological Review 23(2):203-21.

Kaneko, Motohisa. 1996. "Koto kyoiku taishuka no ninaite (Members of Popularization of Higher Education).” Report on Multimedia Education, 91: 37-59. Open University of Japan. [In Japanese]

Kuwahara, Motoko. 2001. “Japanese Women in Science and Technology.” Minerva 39(2):20316.

Lee, Kristen Schultz. 2010. "Parental educational investments and aspirations in Japan." Journal of Family Issues 31(12): 1579-1603.

Levanon, A., P. England, and P. Allison. 2009. "Occupational Feminization and Pay: Assessing Causal Dynamics Using 1950-2000 U.S. Census Data.” Social Forces 88(2):865-91.

Li, Shangbo. 2019. "The Beginning of the End? Changes in Junior Colleges in Japanese Female Higher Education.” Pp. 167-79 in Gender and the Changing Face of Higher Education in Asia Pacific, edited by D. E. Neubauer and S. Kaur. Cham: Springer International Publishing.

Machin, Stephen and Patrick A. Puhani. 2003. "Subject of Degree and the Gender Wage Differential: Evidence from the UK and Germany." Economics Letters 79(3):393-400.

Mann, Allison and Thomas A. DiPrete. 2013. "Trends in Gender Segregation in the Choice of Science and Engineering Majors.” Social Science Research 42(6):1519-41. 
Michelmore, Katherine, and Sharon Sassler. 2016. "Explaining the Gender Wage Gap in STEM: Does Field Sex Composition Matter?" RSF: The Russell Sage Foundation Journal of the Social Sciences 2(4):194-215.

Milgrom, Eva M. Meyersson and Trond Petersen. 2006. "The Glass Ceiling in the U.S. and Sweden: Lessons from the Family- Friendly Corner of the World, 1970-1990.” Pp. 156-211 in The Declining Significance of Gender?, edited by F. D. Blau, M. C. Brinton, and D. B. Grusky. Russell Sage Foundation.

Ministry of Education, Culture, Sports, Science, and Technology 2019. Statistical Abstract. Miura, Mari. 2018. “Persistence of Women's Under-Representation.” Pp. 185-201 in Japan Decides 2017, edited by R. J. Pekkanen, S. R. Reed, E. Scheiner, and D. M. Smith. Cham: Springer International Publishing.

Miyoshi, Koyo. 2008. "Male-Female Wage Differentials in Japan.” Japan and the World Economy 20(4):479-96.

Morgan, Stephen L., Dafna Gelbgiser, and Kim A. Weeden. 2013. "Feeding the Pipeline: Gender, Occupational Plans, and College Major Selection.” Social Science Research 42(4):989-1005.

Morris, Martina and Bruce Western. 1999. "Inequality in Earnings at the Close of the Twentieth Century." Annual Review of Sociology 25(1):623-57.

Murakami, Yumiko and Francesca Borgonovi. 2018. "Japan Needs Gender Equality.” Science 362(6411):133-133.

Nakata, Yoshifumi. 1997. "Nihon Ni Kokeru Danjyo Chingin Kakusa No Yoinbunseki (AnalYses of Factors Contributing to the Sex Pay Gap in Japan).” Pp. 173-99 in Koyo kanko no henka to jyosei rodo (Changes in Employment Practice and Women's Work), edited by H. Chuma and T. Suruga. Tokyo, Japan: University of Tokyo Press. [In Japanese]

Nakazawa, Wataru. 2016. Why Is Public Expenditure on Education in Japan Low?: Reexamining the Public Function of Education. Osaka University Press. 
NHK Broadcasting Culture Research Institute 2019. Gendai Nihonjin no ishiki kōzō

(Contemporary Japanese Value Structure). NHK Publishing. [In Japanese]

Ogawa, Mariko. 2017. "History of Women's Participation in STEM Fields in Japan.” Asian Women 33(3):65-85.

Ono, Hiroshi. 2004. “Are Sons and Daughters Substitutable?” Journal of the Japanese and International Economies 18(2):143-60.

Ono, Hiroshi. 2008. “Training the Nation's Elites: National-Private Sector Differences in Japanese University Education.” Research in Social Stratification and Mobility 26(4):34156.

Osumi, Noriko. 2006. "Woman Scientists in Japan: Their Situation and Goals." IUBMB Life (International Union of Biochemistry and Molecular Biology: Life) 58(5-6):273-78.

Osumi, Noriko. 2018. “Japan’s Woman Problem.” Nature Index. Retrieved January 2, 2020 (https://www.natureindex.com/news-blog/japans-woman-problem).

Petersen, Trond and Laurie A. Morgan. 1995. "Separate and Unequal: Occupation-Establishment Sex Segregation and the Gender Wage Gap.” American Journal of Sociology 101(2):32965.

Raymo, James M., Hyunjoon Park, Yu Xie, and Wei-jun Jean Yeung. 2015. "Marriage and Family in East Asia: Continuity and Change." Annual Review of Sociology 41(1):471-92.

Ridgeway, Cecilia L. 2001. “Gender, Status, and Leadership.” Journal of Social Issues 57(4):637-55.

Ridgeway, Cecilia L. 2011. Framed by Gender: How Gender Inequality Persists in the Modern World. Oxford University Press.

Ridgeway, Cecilia L. and Shelley J. Correll. 2004. "Unpacking the Gender System: A Theoretical Perspective on Gender Beliefs and Social Relations." Gender \& Society 18(4):510-31.

Rosenbluth, Frances McCall, ed. 2007. The Political Economy of Japan’s Low Fertility. Stanford, Calif: Stanford University Press. 
Shauman, Kimberlee A. 2016. "Gender Differences in the Early Career Outcomes of College Graduates: The Influence of Sex-Type of Degree Field Across Four Cohorts.” RSF: The Russell Sage Foundation Journal of the Social Sciences 2(4):152-93.

Shirahase, Sawaka and Hiroshi Ishida. 1994. "Gender Inequality in the Japanese Occupational Structure.” International Journal of Comparative Sociology 35(3/4):188-206.

Starobin, Soko S. 2002. "Community Colleges in Japan and the Social Status of Japanese Women." Community College Journal of Research and Practice 26(6):493-502.

Takahashi, Hiroto. 2009. Public Universities in 20th Century Japan. [Nijyuseiki Nihon no Kouritsu Daigaku] Nihon Tosho Center. [In Japanese]

Takenoshita, Hirohisa. 2020. "The Gender Wage Gap in Four Asian Countries: Japan, Singapore, South Korea, and Taiwan.” Pp. 41-59 in Low Fertility in Advanced Asian Economies, edited by S. Matsuda. Singapore: Springer Singapore.

Tam, Tony. 1997. "Sex Segregation and Occupational Gender Inequality in the United States: Devaluation or Specialized Training?” American Journal of Sociology 102(6):1652-92. Tomaskovic-Devey, Don and Sheryl Skaggs. 2002. "Sex Segregation, Labor Process Organization, and Gender Earnings Inequality." American Journal of Sociology 108(1):10228.

Tsuya, Noriko O., Larry L. Bumpass, and Minja Kim Choe. 2000. "Gender, Employment, and Housework in Japan, South Korea, and the United States." Review of Population and Social Policy 9:195-220.

Turner, Sarah E. and William G. Bowen. 1999. "Choice of Major: The Changing (Unchanging) Gender Gap.” Sociology of Education 52(2):289-313.

Uchikoshi, Fumiya. 2019. "Dissecting Educational Assortative Marriage in Japan: The Role of Institutional Changes in Higher Education.” Paper presented at 2019 ISA RC28 Summer Meeting at Princeton University, August 15. 
Uchikoshi, Fumiya and Ryota Mugiyama. 2020a. "Trends in Occupational Sex Segregation in Japan: A Decomposition Analysis of Census Data, 1980-2005." Japanese Journal of Population Studies: 56. (Online first)

Uchikoshi, Fumiya and Ryota Mugiyama. 2020b. Declining Trends in Occupational Segregation by Gender in Japan: An Evaluation of Gender Revolution, Economic Restructuring, and Changing Demographic Composition. Unpublished Manuscript.

U.S. Bureau of Labor Statistics. 2020. Occupational Outlook Handbook. Retrieved March 2, 2020 (https://www.bls.gov/ooh/healthcare/registered-nurses.htm).

U.S. Economics and Statistics Administration. 2017. Women in STEM: 2017 Update. Retrieved March 2, 2020 (https://www.spglobal.com/_media/documents/women-in-stem-2017update.pdf).

Xie, Yu, and Kimberlee A. Shauman. 2003. Women in Science: Career Processes and Outcomes. Cambridge: Harvard University Press.

Yamaguchi, Kazuo. 2019. Gender Inequalities in the Japanese Workplace and Employment: Theories and Empirical Evidence. Springer.

Yonezawa, Akiyoshi. 2008. "The Expansion and Differentiation of the Japanese Higher Education System and Educational Attainment.” Pp. 113-139 in The 2005 SSM Research Series Volume 5: Structure of Educational Attainment, edited by Akiyoshi Yonezawa. Tokyo: 2005 SSM Survey Committee.

Yonezawa, Akiyoshi, Izumi Nakatsui, and Tetsuo Kobayashi. 2002. "University Rankings in Japan." Higher Education in Europe 27:373-82.

Watanabe, Miyoko. 2019. “Unconscious Bias Limits Women’s Careers.” Nature Index. Retrieved January 2, 2020 (https://www.nature.com/articles/d41586-019-00832-4). World Economic Forum. 2020. Global Gender Gap Report 2020. Retrieved March 7, 2020 (http://www3.weforum.org/docs/WEF_GGGR_2020.pdf). 
van de Werfhorst, Herman G. 2017. "Gender Segregation across Fields of Study in PostSecondary Education: Trends and Social Differentials.” European Sociological Review 33(3):449-64.

van de Werfhorst, Herman G. and Gerbert Kraaykamp. 2001. "Four Field-Related Educational Resources and Their Impact on Labor, Consumption, and Sociopolitical Orientation.” Sociology of Education 74(4):296-317. 
Table 1 List of fields of study, harmonized

\begin{tabular}{|c|c|c|c|}
\hline A. Humanities & & F. Health & \\
\hline 1 & Literature & 38 & Medicine \\
\hline 2 & History & 39 & Dentistry \\
\hline 3 & Philosophy & 40 & Pharmacy \\
\hline 4 & Others & 41 & Nursing \\
\hline B. Social sciences & & 42 & Others \\
\hline 5 & Law and politics & G. Merchant marine & \\
\hline 6 & Commerce and economics & 43 & Merchant marine \\
\hline 7 & Sociology & H. Home economics & \\
\hline 8 & Others & 44 & Home economics \\
\hline C. Physical sciences & & 45 & Food science \\
\hline 9 & Mathematics & 46 & Clothing \\
\hline 10 & Physics & 47 & Housing \\
\hline 11 & Chemistry & 48 & Child \\
\hline 12 & Biology & I. Pedagogy & \\
\hline 13 & Geography & 49 & Pedagogy \\
\hline 14 & Others & 50 & Elementary school education \\
\hline D. Engineering & & 51 & Junior high school education \\
\hline 15 & Mechanical engineering & 52 & High school education \\
\hline 16 & Telecommunications engineering & 53 & Specialized subjects education \\
\hline 17 & Civil engineering & 54 & Visually impaired education \\
\hline 18 & Applied chemistry & 55 & Deaf education \\
\hline 19 & Applied science & 56 & Special school education \\
\hline 20 & Nuclear engineering & 57 & Kindergarten education \\
\hline 21 & Mining engineering & 58 & Physical education \\
\hline 22 & Metallurgical engineering & 59 & Others \\
\hline 23 & Textile engineering & J. Fine arts & \\
\hline 24 & Marine engineering & 60 & Fine arts \\
\hline 25 & Aeronautical engineering & 61 & Design \\
\hline 26 & Engineering management & 62 & Music \\
\hline 27 & Crafts & 63 & Others \\
\hline 28 & Others & K. Others & \\
\hline E. Agricultural sciences & & 64 & Liberal arts \\
\hline 29 & Agricultural sciences & 65 & General science \\
\hline 30 & Agricultural chemistry & 66 & Liberal arts (humanities and social science) \\
\hline 31 & Agricultural engineering & 67 & Liberal arts (science) \\
\hline 32 & Agricultural economics & 68 & Others \\
\hline 33 & Forestry & & \\
\hline 34 & Forest products & & \\
\hline 35 & Veterinary medicine & & \\
\hline 36 & Fisheries science & & \\
\hline 37 & Others & & \\
\hline
\end{tabular}


Table 2 Contribution to the segregation index from Non-STEM, STEM, and health fields

$$
\sum_{j \in \text { NonSTEM }} D_{j t} \sum_{j \in S T E M} D_{j t} \quad \sum_{j \in \text { Health }} D_{j t} \quad D_{t}
$$

Non-STEM STEM Health Total

\begin{tabular}{cccccc}
\hline Total & & & & & \\
& & & & & \\
1975 & 50.1 & 14.4 & 3.6 & 68.1 \\
1990 & 40.2 & 13.3 & 2.4 & 55.9 \\
2005 & 28.0 & 12.4 & 3.4 & 43.8 \\
2019 & 22.1 & 10.8 & 5.9 & 38.9 \\
National & & & & \\
1975 & 39.3 & 21.4 & 4.4 & 65.1 \\
1990 & 27.4 & 18.8 & 2.3 & 48.5 \\
2005 & 17.0 & 19.2 & 4.7 & 40.9 \\
2019 & 13.7 & 17.4 & 5.9 & 37.0
\end{tabular}

Public

$\begin{array}{lllll}1975 & 49.3 & 9.1 & 6.8 & 65.2 \\ 1990 & 39.5 & 10.0 & 4.1 & 53.6 \\ 2005 & 22.0 & 13.1 & 11.6 & 46.7 \\ 2019 & 16.0 & 13.6 & 13.7 & 43.3\end{array}$

Private

\begin{tabular}{lllll}
1975 & 52.6 & 13.0 & 3.4 & 69.1 \\
1990 & 44.1 & 11.8 & 2.4 & 58.3 \\
2005 & 31.6 & 10.6 & 2.4 & 44.6 \\
2019 & 25.0 & 9.0 & 5.1 & 39.1 \\
\hline
\end{tabular}




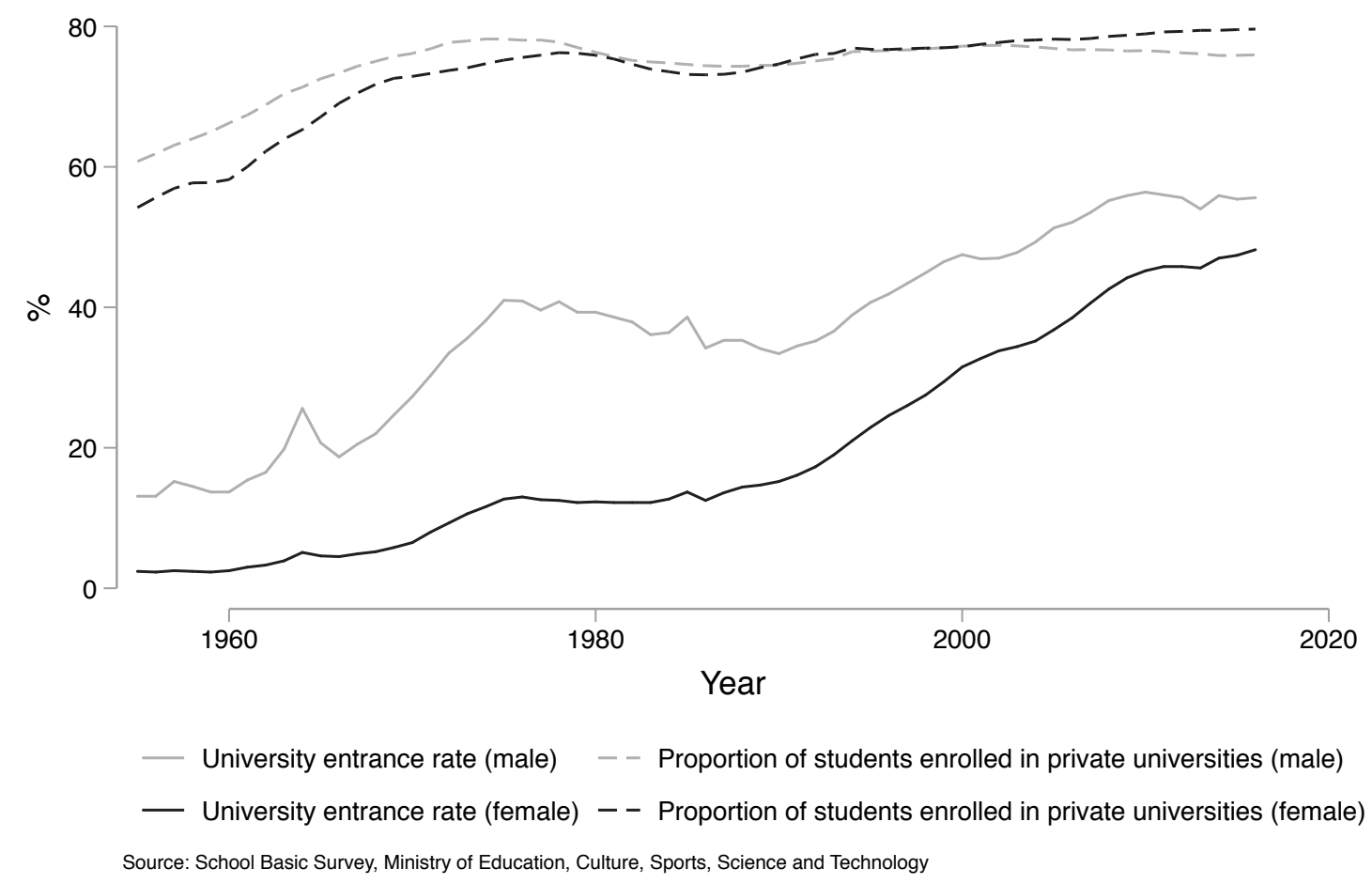

Figure 1 Trends in university enrollment in Japan 


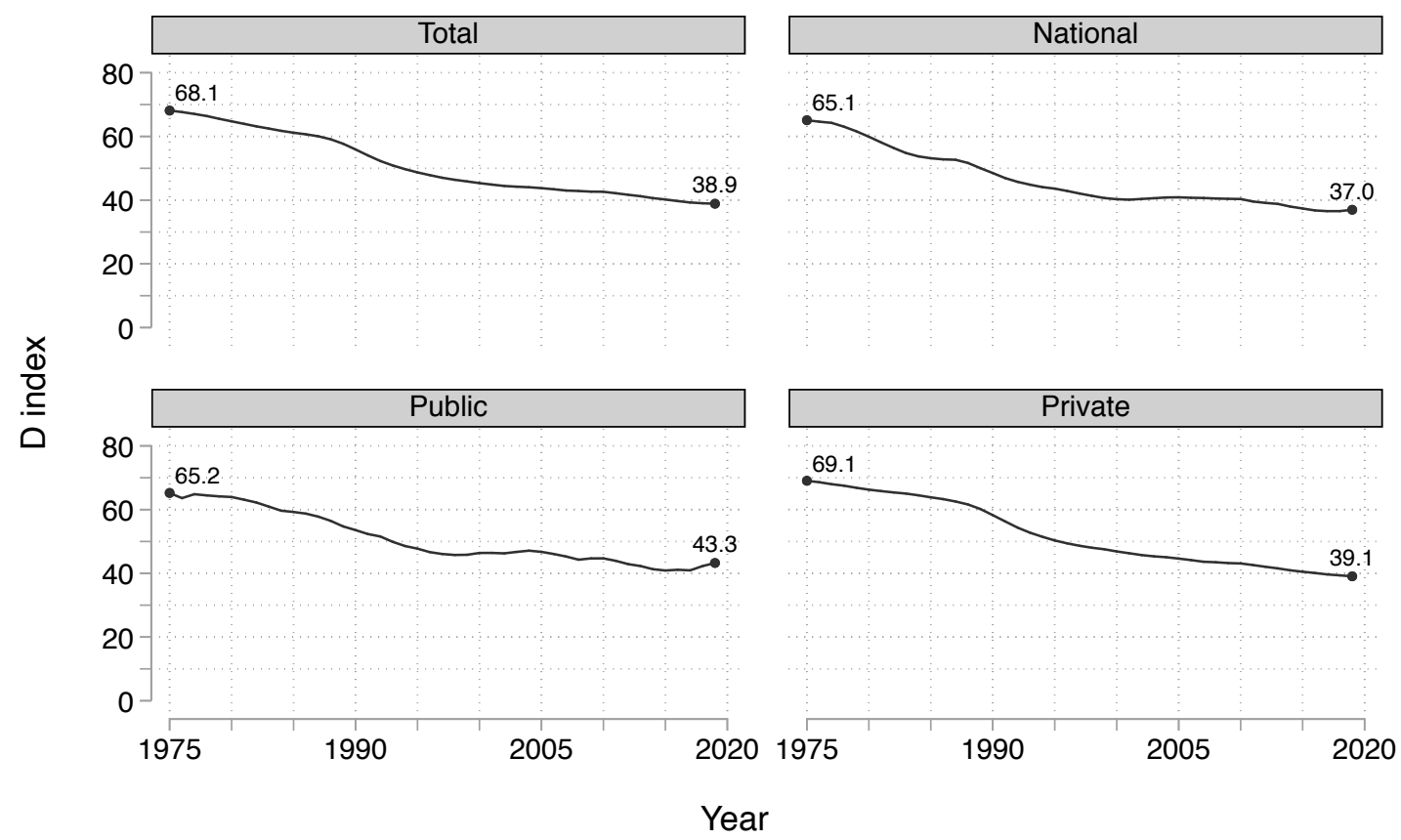

Figure 2 Trends in sex segregation by field of study in Japan (68 fields), 1975-2019

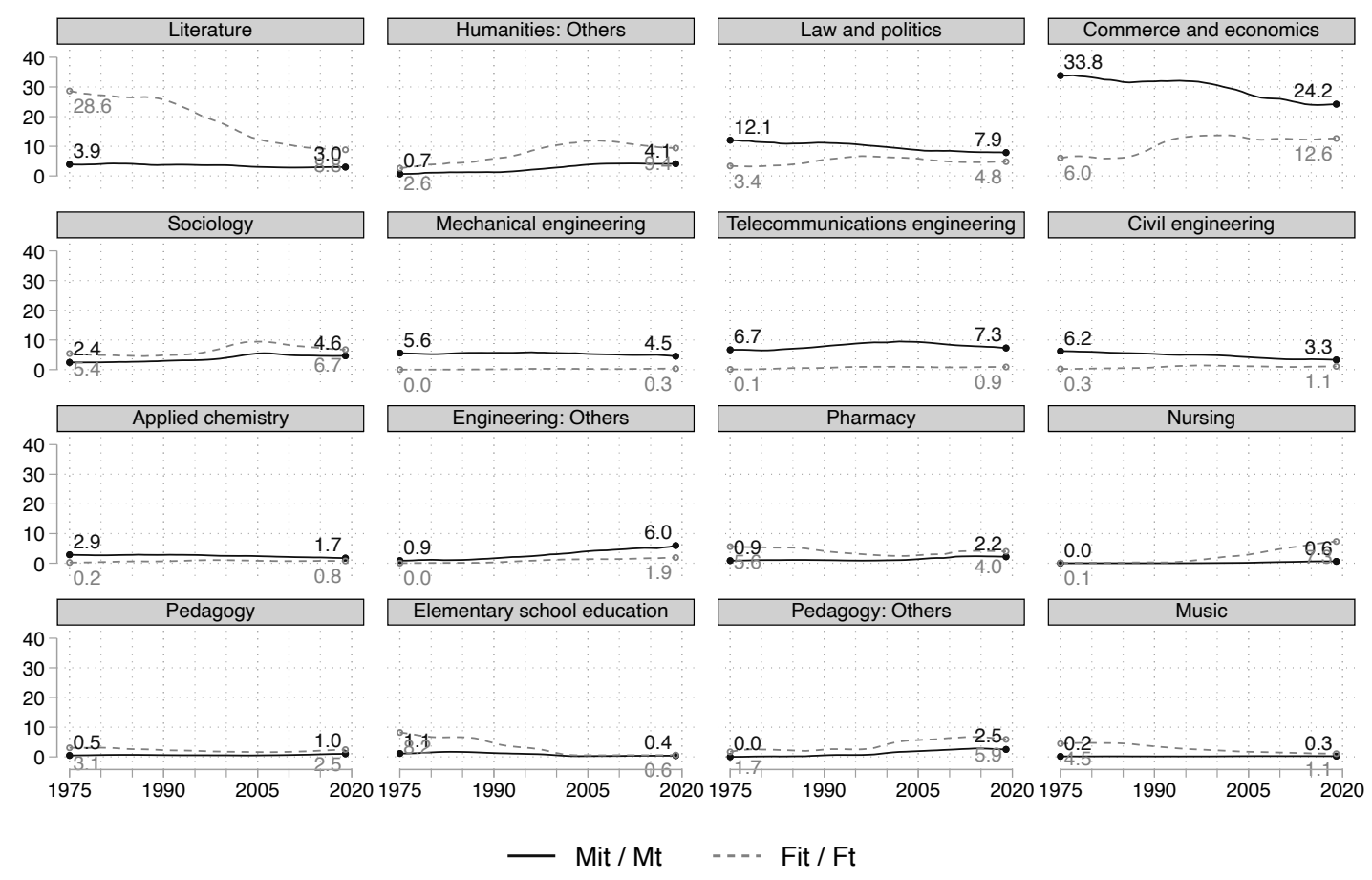

Figure 3 Trends in the proportion of all men and of all women in selected fields, 1975-2019 (Total) 


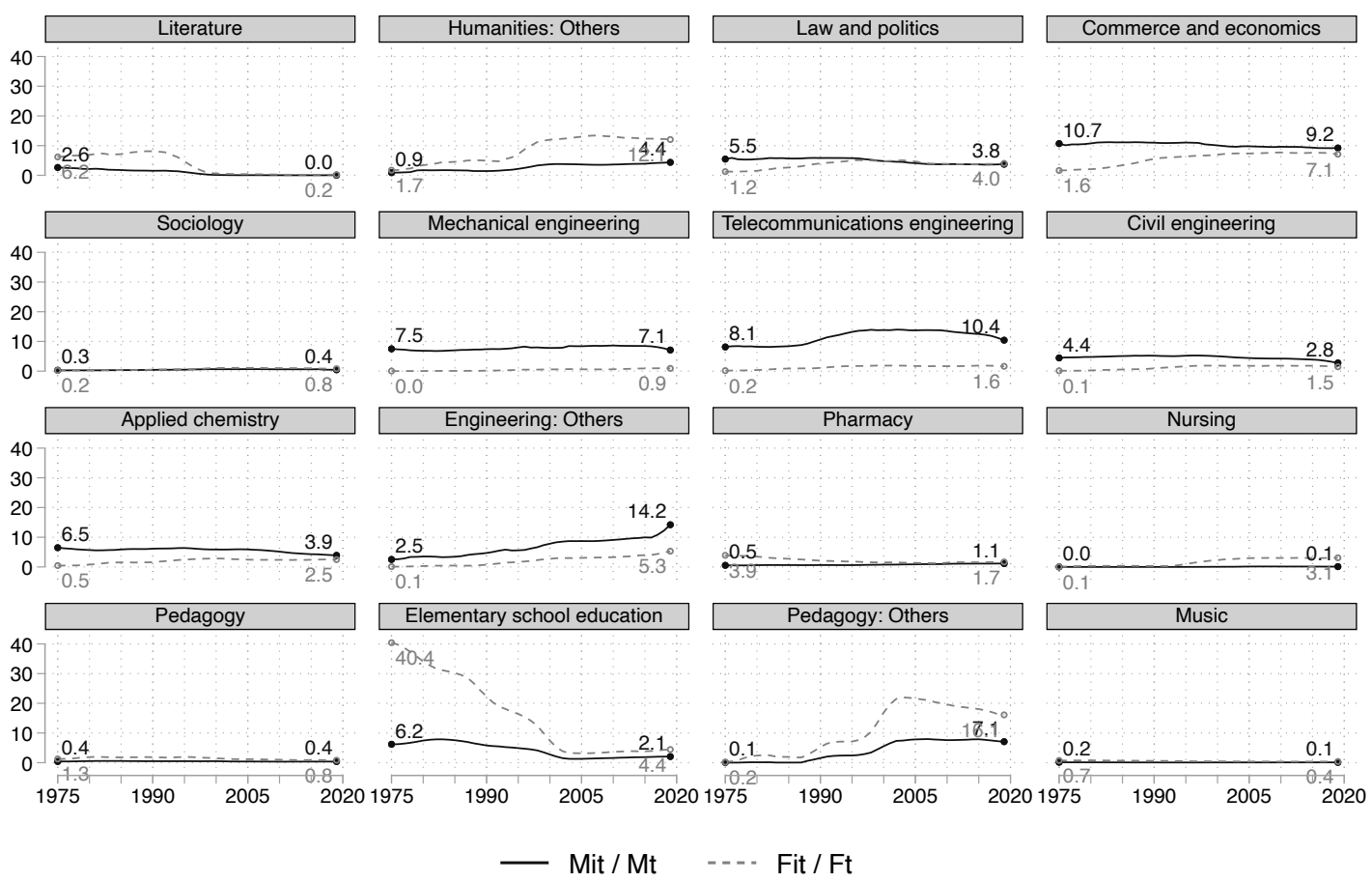

Figure 4 Trends in the proportion of all men and of all women in selected fields (National)

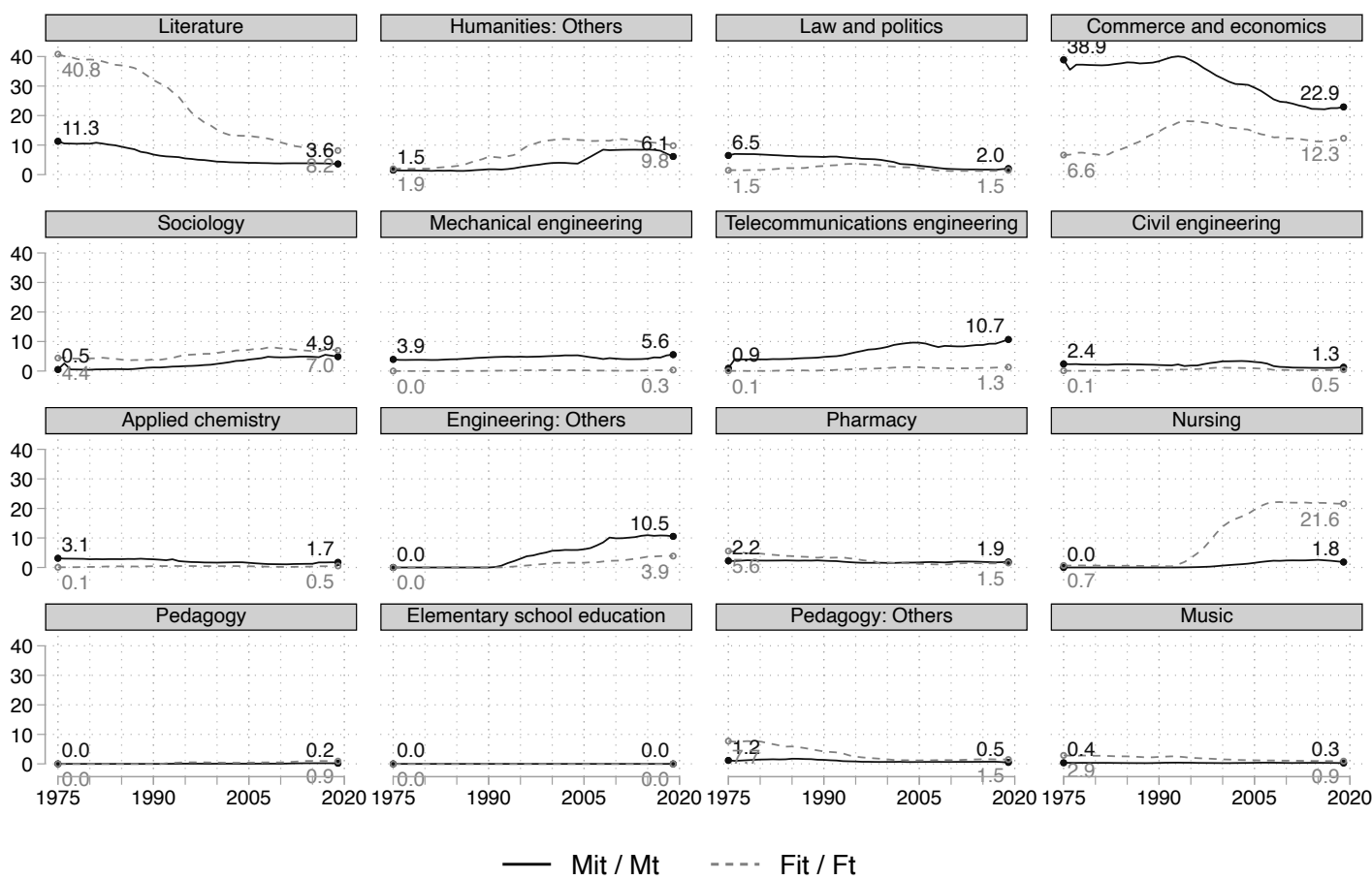

Figure 5 Trends in the proportion of all men and of all women in selected fields (Public) 


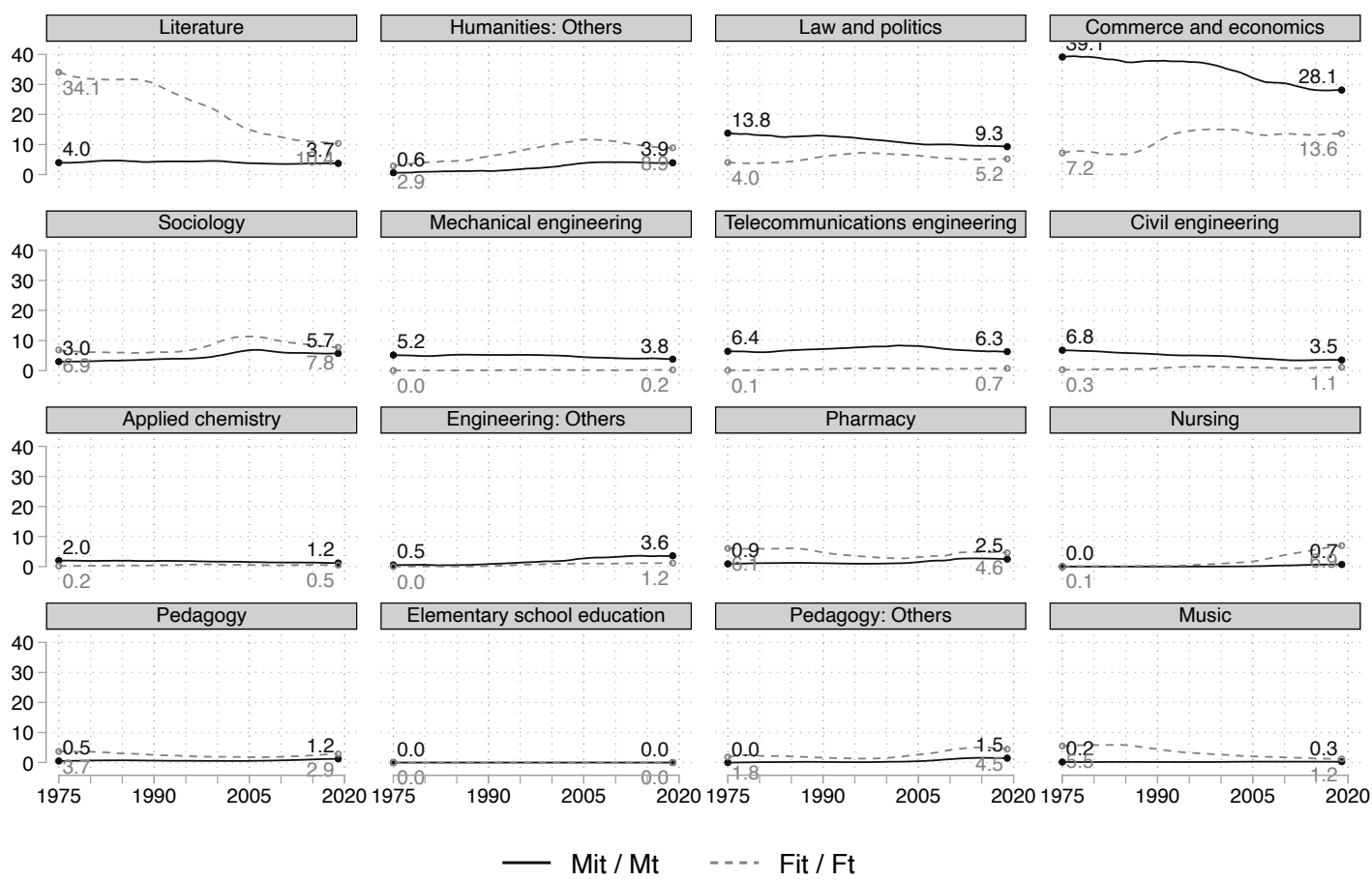

Figure 6 Trends in the proportion of all men and of all women in selected fields (Private)

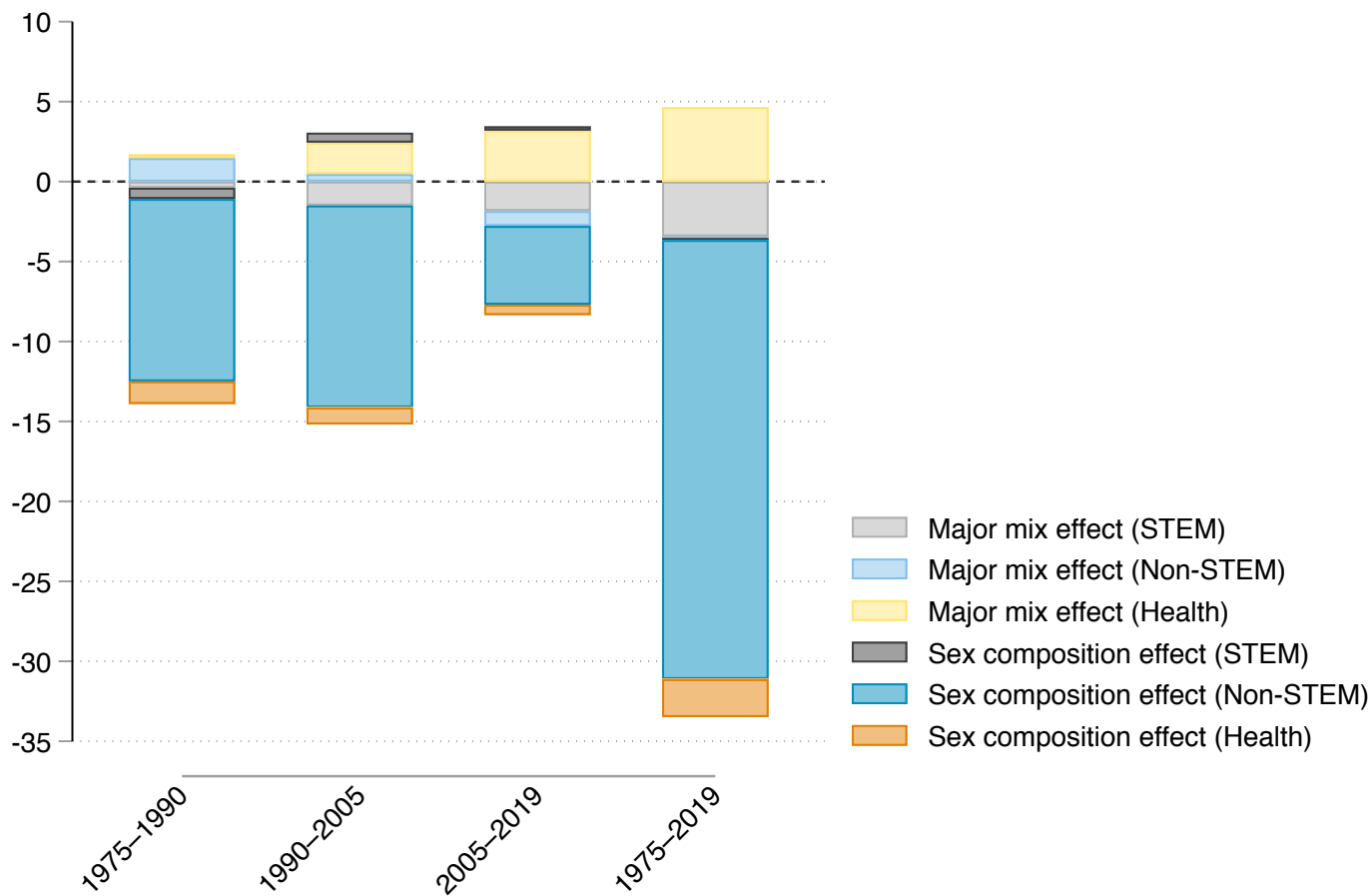

Figure 7 Decomposition results of trends in sex segregation by college major (Total) 


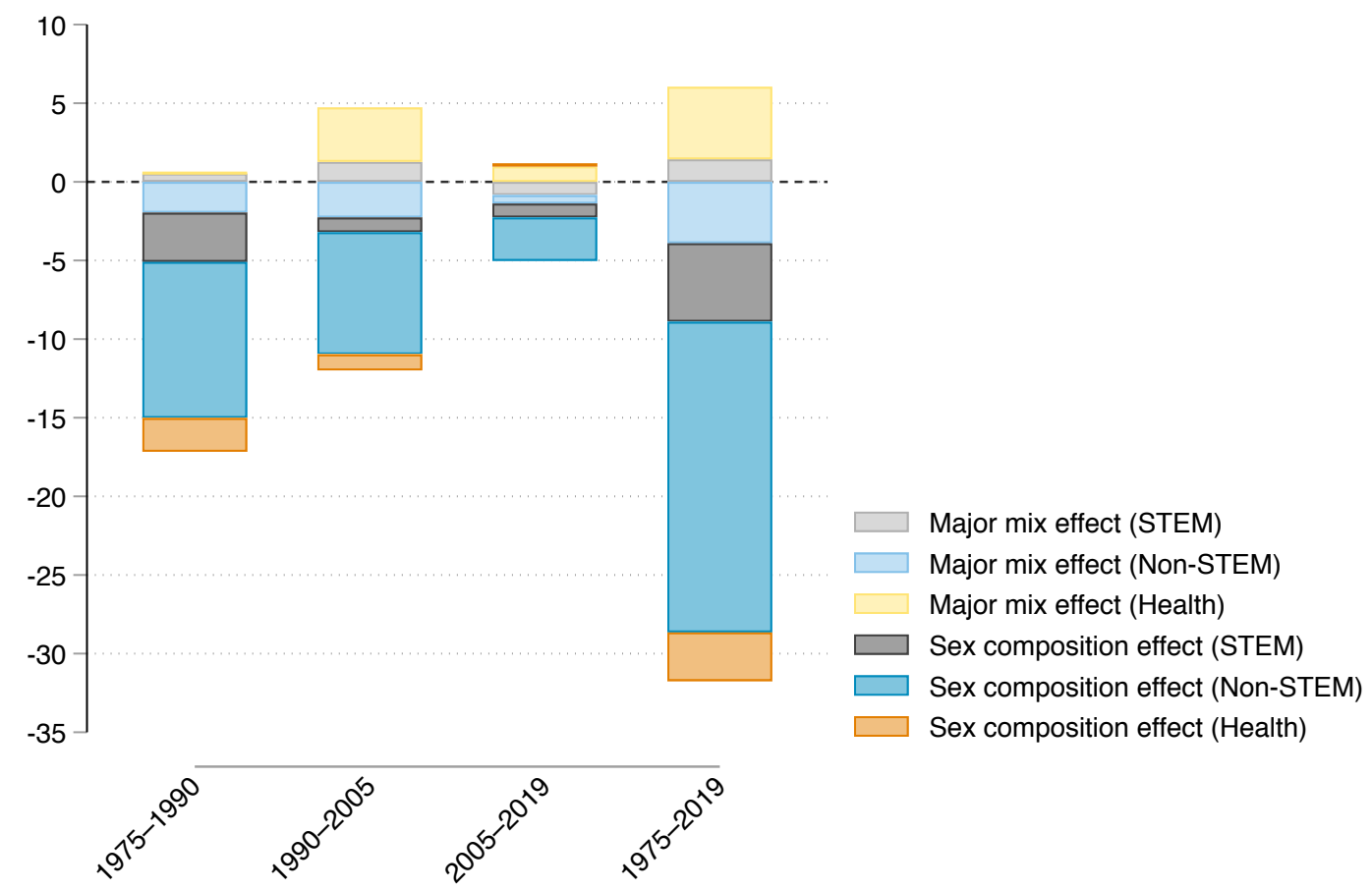

Figure 8 Decomposition results of trends in sex segregation by college major (National)

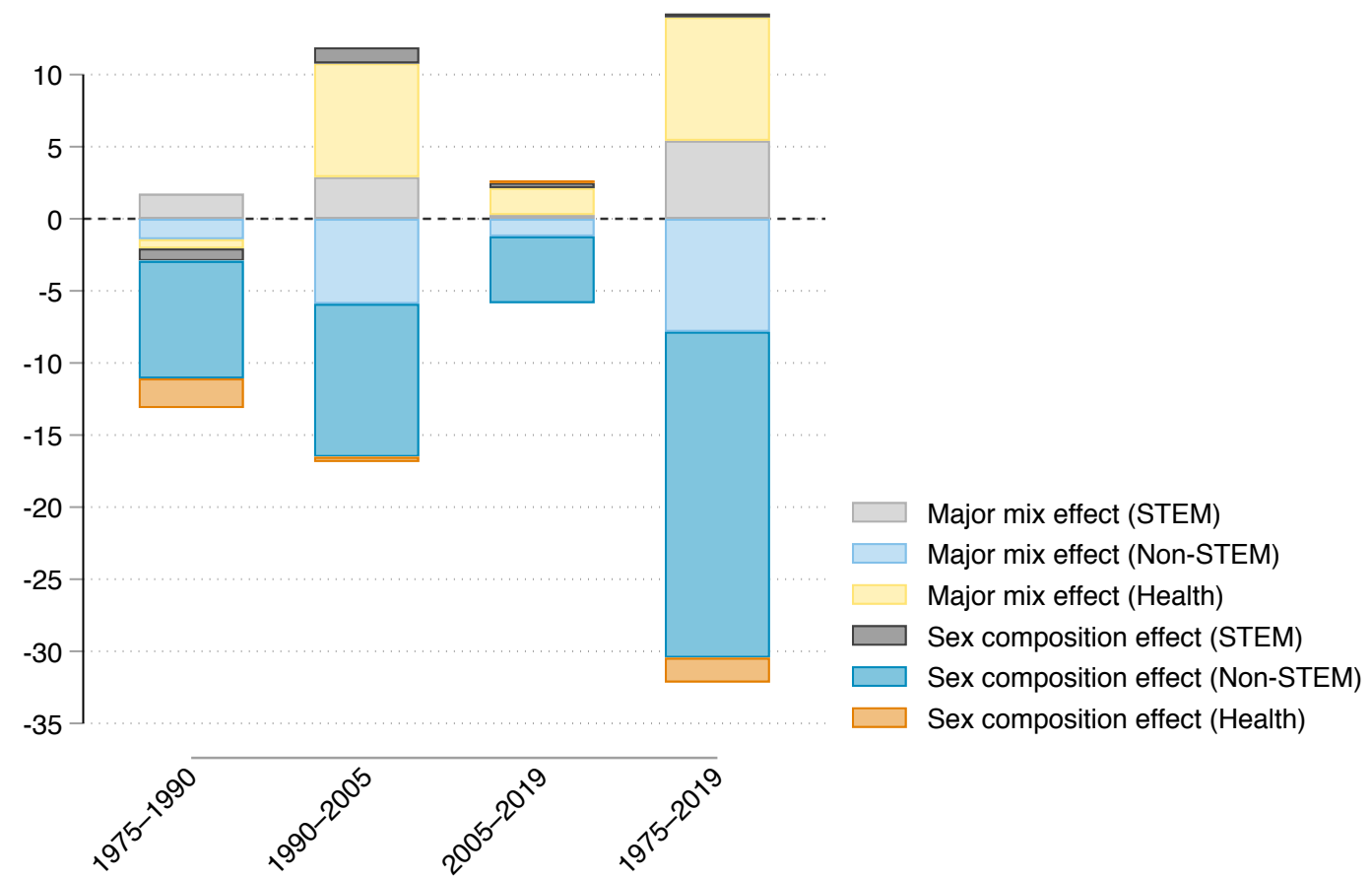

Figure 9 Decomposition results of trends in sex segregation by college major (Public) 


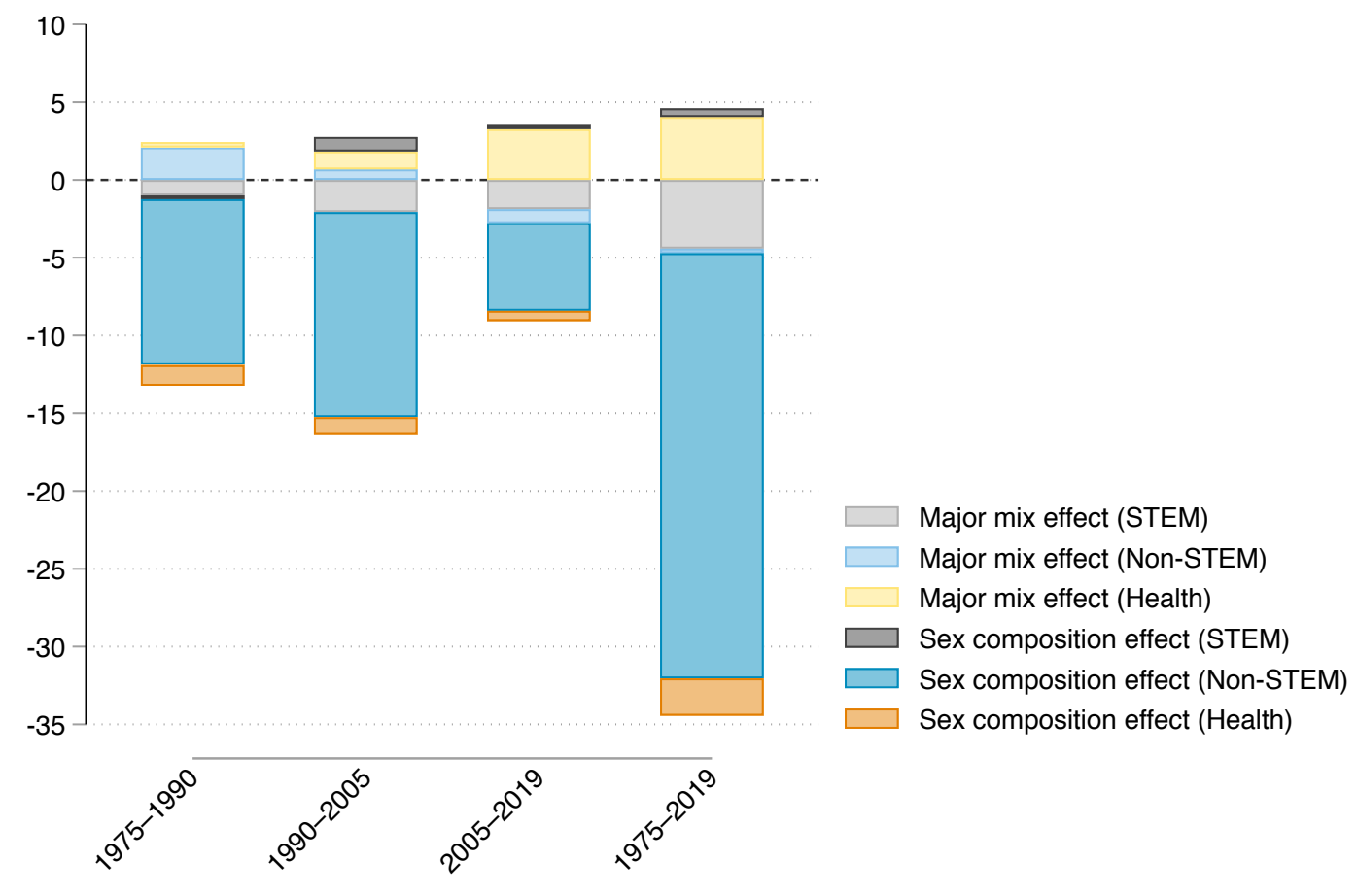

Figure 10 Decomposition results of trends in sex segregation by college major (Private) 


\section{Appendix}

The university classification scheme developed by Kaneko (1996) and Yonezawa (2008) emphasized educational expansion, led by private universities in Japan during the 1960s to 1970s, and distinguished these newly-established universities from other national or private universities. This also divides prestigious private universities, which were established around the year of the imperial university order in 1918 - the first regulation giving approval for the establishment of universities - from other non-selective private universities. A variant of Yonezawa's (2008) scheme was defined as follows:

1. National/public universities

2. Prestigious private universities: Keio, Waseda, Meiji, Rikkyo, Hosei, Chuo, Kansai, Kwansei-Gakuin, Doshisha, Ritsumeikan, Gakushuin, and Sophia

3. Private universities established in 1960 or before

4. Private universities established after 1960

Appendix Table 1 Distribution of university prestige by sex (row percent)

\begin{tabular}{lccccc}
\hline & Prestigious & Private (1960 & Private (after & \\
& National/public & private & or before) & $1960)$ & $\mathrm{n}$ \\
\hline Male & 27.4 & 17.3 & 34.9 & 20.4 & 1,122 \\
Female & 25.5 & 11.1 & 31.0 & 32.4 & 623 \\
\hline
\end{tabular}

Appendix Table 2 Distribution of majors by sex and university prestige (row percent)

\begin{tabular}{lcccccccc}
\hline & \multicolumn{3}{c}{ Male } & \multicolumn{3}{c}{ Female } \\
& Non-STEM & STEM & Health & $\mathrm{n}$ & Non-STEM & STEM & Health & $\mathrm{n}$ \\
\hline National/public & 41.7 & 52.1 & 6.2 & 227 & 70.4 & 18.9 & 10.7 & 200 \\
Prestigious private & 77.8 & 22.2 & 0.0 & 389 & 97.1 & 2.9 & 0.0 & 191 \\
Private (1960 or before) & 63.0 & 35.0 & 2.1 & 194 & 90.1 & 6.8 & 3.1 & 69 \\
Private (after 1960) & 69.6 & 24.2 & 6.2 & 307 & 83.5 & 3.5 & 13.0 & 159 \\
\hline
\end{tabular}

